Johnson sees the creation of an informed public as the best vehicle for change. As a contribution, he offers appendices that rate various kinds of animal products in terms of food quality, animal welfare and environmental impact. Genuinely wild game comes out best on each scale, whereas the main large-scale factory-farm products - battery eggs, intensively reared poultry and all nonfree-range pig products - are near the bottom on all three counts. Only farmed fish are, in Johnson's opinion, worse for the environment. In animal-welfare terms, intensively reared 'white' veal is still among the worst offenders, because much of it is imported from the continent, where veal calves are kept in dark, individual crates, even though such methods of rearing calves have been banned in Britain. Absolute zero on the welfare scale, however, is reserved for pâté de foie gras.

Factory farming has arrived with stealth, and grown to a size that makes it difficult to dislodge; but there are grounds for hoping that change is possible. Inroads have been made in several countries, largely on welfare grounds.

\section{Making the difference}

Norman Myers

The Earth in Transition: Patterns and Processes of Biotic Impoverishment. Edited by George M. Woodwell. Cambridge University Press: 1991. Pp.530. £30, \$49.50.

GEORGE Woodwell, president of the Woods Hole Research Center in Massachusetts, has been pondering the nature of biotic impoverishment since the mid-1950s when, using ionizing radiation, he destroyed all life in a sample plot of the Brookhaven Forest in New York State. Over the years (during one of which he served as president of the Ecological Society of America), he has investigated the consequences of many other types of human activities on natural systems, including forests, grasslands, tundras and aquatic habitats. He has concluded that we ought to focus not so much on the end results of biotic impoverishment - the graphic outcomes such as species extinctions - but on the nature of impoverishment itself, that is, the causes, courses and consequences of the Earth's biota in decline.

A worthy enquiry. What, for instance, is the character, extent and likely outcome of our current co-opting of 40 per cent of plant growth worldwide, as calculated by Peter Vitousek, Paul Ehrlich and their colleagues at Stanford Uni-
After banning individual crates for veal calves, the British government has now announced - in a development too recent for inclusion in Factory Farming - that it will also require individual sow stalls to be phased out. Sweden is now into the third year of a ten-year phaseout period that will eliminate all the most-confining systems of animal raising, and give every Swedish farm animal the right to an environment that allows freedom to move and meets minimal behavioural needs. In Switzerland, battery cages for hens will become illegal on 1 January 1992. Andrew Johnson's book shows that such moves are necessary not only because of our ethical obligations to animals, but also to preserve our environment and the quality of our food supply. If each nation would take what is most progressive from the others, we would already be a long way down the road towards ensuring that farm animals have some kind of life, and not only a mere existence.

Peter Singer is director of the Centre for Human Bioethics, Monash University, Clayton, Victoria 3168, Australia.

versity? What does our present understanding, meagre as it is, tell us about what could happen when there are - as there soon will be - twice as many people on Earth, demanding three times as much food and fibre? If we could co-opt 80 per cent or more of primary productivity, how would that affect the millions of other species that share the planetary ecosystem with us and how would that affect the human enterprise?

So too with the question of mass extinction of species. We hear much of how we are about to eliminate species in numbers that will match those of the 'great dying' at the close of the Cretaceous, when roughly half of all life forms are thought to have disappeared. How about mass elimination of genetic variability? During the next century many species that survive the biotic holocaust may well lose most of their subspecies, races and populations; genetically depauperate, they will then be all the less adaptable to drastically changed environments. Which phenomenon will prove to be the most detrimental to the Earth's biota and the many environmental services it supplies? Which will turn out to be the most disruptive for the functioning and ecological stability of natural communities? These questions carry momentous implications, with the effects of depletion probably persisting for at least a million years. Yet our understanding of the processes involved is rudimentary at best.

Hence the importance of this book which presents papers from a late 1986 conference convened by Woodwell to "define the major types of changes in the structure and function of natural communities exposed to chronic disturbance Are [the changes] systematic, cumulative, predictable? At what point in their progress do they become identifiable? To what extent are they reversible?" The book does not seek to come up with diagnostic procedures for evaluating the state of our global experiment; rather it aims to "outline the broad patterns of the transitions underway." As such, it does a first-rate job.

The opening section surveys planetwide patterns of impoverishment, with some emphasis on the effects of air pollution. Successive sections appraise the scope and scale of disturbances stemming from human activities. The reader is guided through a series of revealing case studies, examining forests in Australia, New Zealand, Pacific islands and Amazonia; xeric vegetation in Israel, the Great Basin of the western United States and California; Arctic ecosystems; marine communities in the Red Sea and the deep oceans; and freshwater systems in southern Florida and Ontario. The book concludes with a critical assessment of solutions, highlighting the need for shifts in macro-level policies for conservation of natural communities.

The list of contributors is impressive. It includes such prominent scientists as Herbert Bormann, Margaret Davis, Dieter Mueller-Dombois, Robert Repetto, Zev Naveh, Walter Westman, Fred Grassle, John Cairns, Gus Speth and Donella Meadows. Most of them present an excellent account of their research area, and each paper is introduced with an incisive scene-setting assessment by Woodwell. But one wonders which of these luminaries was so tardy in submitting his or her revised paper that it has taken four years for the book to see the light of day. Do they not recognize the ultra-urgency dictated by the speed of change overtaking the world outside their laboratory windows?

All in all, this is an exceptionally competent book, the only one of its sort to achieve a systematized, also systemic, insight into the question of how far and how fast we are reducing the biotic diversity of the Earth. Although no more than exploratory in certain respects, and offering few conclusive findings, it is a splendid pioneering effort to address one of the great environmental issues of our time. It eschews the (unduly?) dramatic assertions of apocalyptic analysts who proclaim the 'death' of ecosystems. Rather, it concentrates on those factors - less spectacular but more illuminating — that bespeak the progressive ill-health of our biota.

Norman Myers, a consultant in environment and development, is at Upper Meadow, Old Road, Headington, Oxford OX3 8SZ, UK. 